\title{
The antithrombin activity of glucuronic esters of bilirubin
}

\author{
M. KOPEĆ, T. DAROCHA, S. NIEWIAROWSKI, AND J. STACHURSKA \\ From the Laboratories of Clinical Biochemistry and Analytical Chemistry, \\ Institute of Haematology, Warsaw, Poland
}

SYNOPSIS The plasma of patients with pronounced jaundice as well as that of cats with experi- on mental obstructive jaundice inhibits the clotting of normal plasma with thrombin. The influence $\infty$ of different bile constituents-bilirubin, bilirubin glucuronides, sodium salts of bile acid-on the은 clotting of plasma or fibrinogen with thrombin was examined. Bilirubin glucuronides in concentrations above $8 \mathrm{mg}$. \% showed antithrombic activity but other substances were inactive. Glucuronic $\mathbb{C}$ acid and phenolphthalein glucuronide in concentrations up to $100 \mathrm{mg} . \%$ did not have any influence $\frac{\overrightarrow{\mathbb{D}}}{7}$ on the thrombin time.

It is well known that a prolongation of the plasma thrombin time can be observed in the course of liver disease associated with jaundice. According to Ratnoff (1953) and Alagille and Soulier (1957), the prolonged thrombin time in liver disorders is due to a deficiency of some factor in plasma rather than to the appearance of inhibitory substances. Ratnoff's (1953) view is that in plasma there is a co-factor of thrombin-fibrinogen interaction which is defined as 'thrombin accelerator', and its amount may be decreased in liver disease. Other authors suggested an increase of antithrombin activity in the plasma of these patients (Schwarz, Wanner, and Koller, 1951; Sokal, Schmid, and Hörder, 1955). Masure (1956) postulated qualitative modifications in fibrinogen molecules resulting in an increased resistance of fibrinogen to the action of thrombin.

We have found that the plasma of patients with pronounced jaundice, as well as that of cats with experimental obstructive jaundice, inhibits the clotting of normal plasma with thrombin, and the purpose of this paper is to examine the influence of bile constituents on the thrombin-fibrinogen interaction in vitro because it has been found that bilirubin glucuronides exhibit antithrombic activity.

\section{METHODS AND MATERIALS}

Blood from patients and from normal subjects was collected into $0 \cdot 1 \mathrm{M}$ ammonium oxalate in the proportion of one part of anticoagulant to nine parts of blood.

Received for publication 1 December 1960.
Plasma was obtained by centrifuging for $10 \mathrm{~min}$. at $\stackrel{\mathscr{C}}{\oplus}$ 1,500 r.p.m.

Cats' plasma was obtained in the same manner from the animals with experimental obstructive jaundice produced by ligating the choledochus duct and from control cats.

Fibrinogen was prepared from bovine plasma by the method of Blombäck and Blombäck (1957). Co.

Thrombin was purchased from Hoffman la Roche and $\vec{\overrightarrow{ }}$

Bilirubin, glucuronic acid, phenolphthalein glucuronide, sodium salts of choleic, and desoxycholeic and glicocholic acid were commercial preparations. As a solvent for bilirubin, $0.1 \mathrm{M} \mathrm{Na}_{2} \mathrm{CO}_{3}$ was used.

Bilirubin glucuronides were prepared by the method of Cole, Lathe, and Billing (1954) from urine, blood, and 3 bile from human patients with liver disorders. The identity of ester preparations obtained was confirmed by paper chromatography (Schmid, 1957), absorption spectra (Cole et al., 1954), and the direct van den Bergh reaction. 을 The preparations were protein free and freely soluble in $>$ water.

Paalisch buffer was made up of solutions $A$ and B. A Sodium borate 0.05 M 19.108 g. $\mathrm{Na}_{2} \mathrm{~B}_{4} \mathrm{O}_{7} 10 \mathrm{H}_{2} \mathrm{O}$. ..........1,000 ml.

B Boric acid solution in saline, $12.404 \mathrm{~g} . \mathrm{H}_{3} \mathrm{BO}_{3}, 2 \cdot 925 \mathrm{~N}$ g, $\mathrm{NaCl}$, distilled water to $1,000 \mathrm{ml}$.

and 1.2 vol. of $A$ was mixed with $8.8 \mathrm{vol}$. of $B$. The finat? pH should be 7.6.

This buffer was used as a diluent for all reagents unless $\mathbb{\Phi}$ otherwise stated.

\section{METHODS}

The thrombin time was determined as follows:-

Plasma, $0.2 \mathrm{ml}$., or $0.2 \%$ fibrinogen was mixed with $0.2 \mathrm{ml}$. of the substance to be tested or the solvent used 
to prepare the solution of the above substance, and added to $0.1 \mathrm{ml}$. thrombin (diluted in order to obtain a clotting time of 10 to $15 \mathrm{sec}$. in the control system). Prothrombin time was determined by the method of Quick (1935) using rabbit brain thromboplastin.

The recalcification time was tested after adding $0.2 \mathrm{ml}$. plasma to the same volume of $0.025 \mathrm{M} \mathrm{CaCl}_{2}$.

The inhibitory influence of bile constituents on the prothrombin and recalcification times was determined after adding one volume of the substance to be tested to one volume of plasma.

The concentration of bilirubin and bilirubin glucuronides in plasma samples and in the preparations of bilirubin esters was determined by the method of Malloy and Evelyn (1937) using a Coleman D 206 B spectrophotometer.

\section{RESULTS}

ANTITHROMBIC ACTIVITY OF ICTERIC PLASMAS We have observed a markedly prolonged thrombin time in some patients with pronounced jaundice. Patients' and normal plasmas were mixed in various proportions and the thrombin time was determined in each mixture. A significant inhibitory influence of icteric plasma can be seen from the curve shown in Fig. 1. The same phenomenon was observed when the mixtures of normal and icteric plasma of cats were examined (Fig. 2).

INFLUENCE OF BILIRUBIN, BILIRUBIN GLUCURONIDES, GLUCURONIC ACID, PHENOLPHTHALEIN GLUCURONIDES, AND SODIUM SALTS OF BILE ACIDS ON THROMBIN TIME The influence of all these substances on clotting of

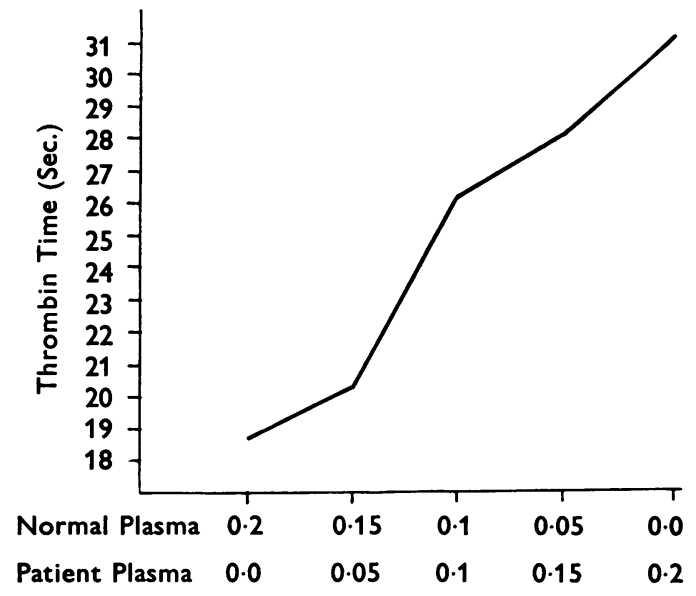

FIG. 1. Influence of icteric plasma on the thrombin tim? of normal plasma. Patient was suffering from obstructive jaundice due to cholelithiasis. Level of total bilirubin in serum is $51 \mathrm{mg} . \%$ and of bilirubin glucuronides $40.3 \mathrm{mg} . \%$. normal plasma and on fibrinogen with thrombin was examined (Figs. 3 and 4). It was found that bilirubin up to a concentration of $200 \mathrm{mg} . \%^{1}$ and sodium salts of bile acids up to the concentration of $100 \mathrm{mg}$. $\%$ did not influence the thrombin time. On the contrary, bilirubin glucuronides showed a significant inhibitory influence in concentrations above $8 \mathrm{mg}$. $\%$. Therefore we examined glucuronic acid and phenolphthalein glucuronide and found that these substances in concentrations up to $100 \mathrm{mg}$. \% did not have any influence on thrombin time.

THE INFLUENCE OF BILIRUBIN GLUCURONIDES ON PROTHROMBIN AND RECALCIFICATION TIMES It can be seen from Table I that the thrombin time of plasma and of fibrinogen as well as of the prothrombin and recalcification times of plasma are prolonged in the presence of bilirubin glucuronides.

${ }^{1}$ The values refer to the initial concentrations of solutions which were examined.

\section{DISCUSSION}

It appears that bilirubin glucuronides inhibit thrombin-fibrinogen interaction, while other tested bile constituents are not active. We were not able to confirm the finding quoted by Scheraga and Laskowski (1957) concerning the inhibition of fibrinogen-fibr in conversion by bile acids.

The possibility cannot be excluded that the different reactivity of bilirubin and its esters is related

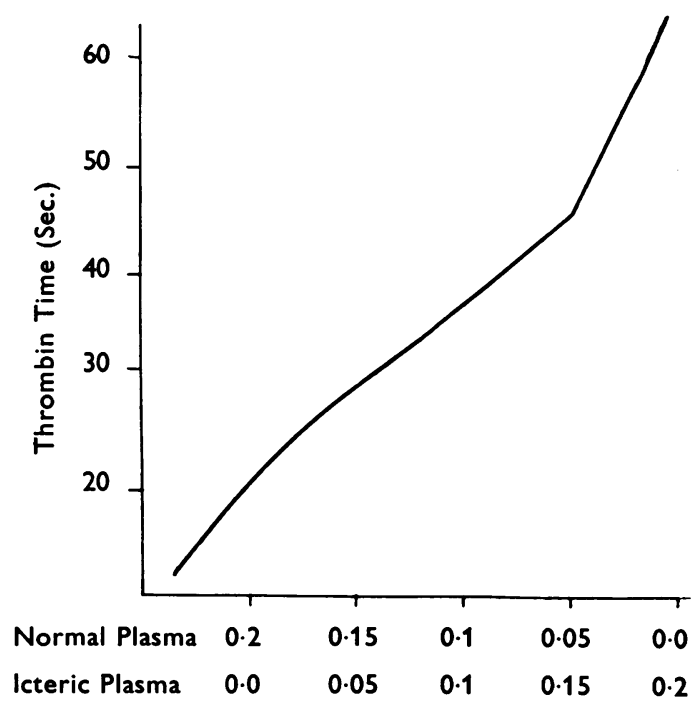

FIG. 2. Influence of icteric cat plasma on the thrombin time of normal cat plasma. Level of total bilirubin in serum $21.7 \mathrm{mg} . \%$ and of bilirubin glucuronides $17 \mathrm{mg} . \%$. 


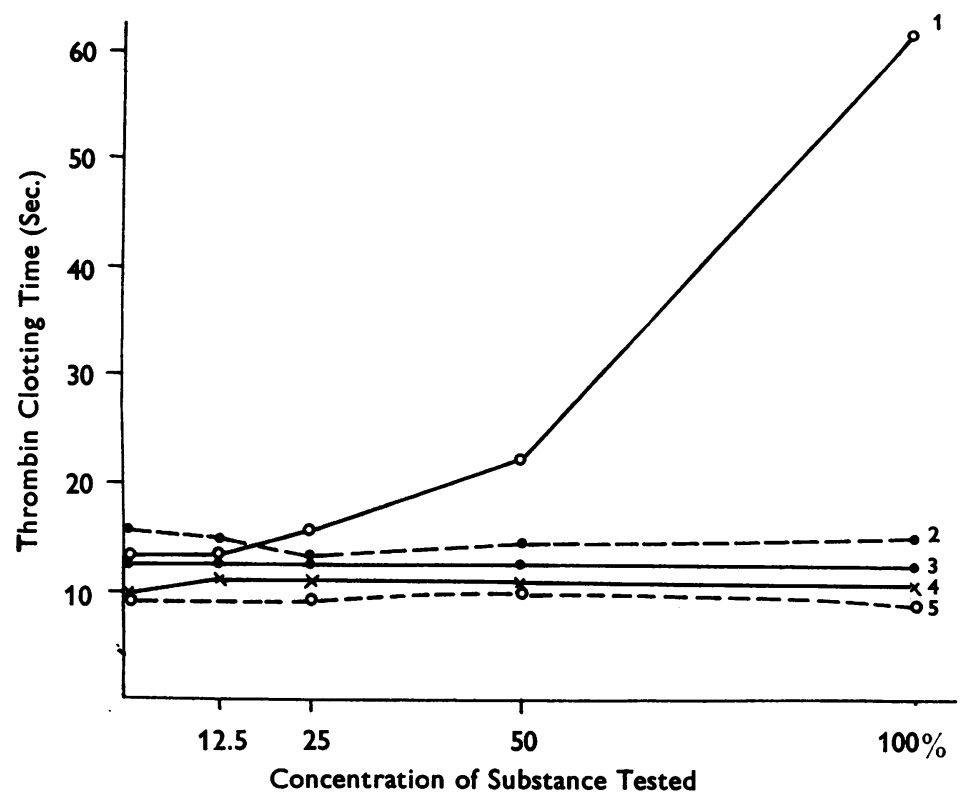

FIG. 3. Influence of free bilirubin, bilirubin glucuronides, glucuronic acids, phenolphthalein glucuronides and bile acid salts on the clotting time of normal plasma with thrombin. Initial concentrations: Bilirubin esters, $17.5 \mathrm{mg}$. \%; glycocholic acid, $20 \mathrm{mg}$. \%; free bilirubin, $200 \mathrm{mg}$. \%; glucuronic acid, phenolphthalein glucuronide, sodium glycocholate, sodium deoxycholate, sodium salt of choleic acid, $100 \mathrm{mg}$. \%; and cholic acid, $25 \mathrm{mg}$. \%.

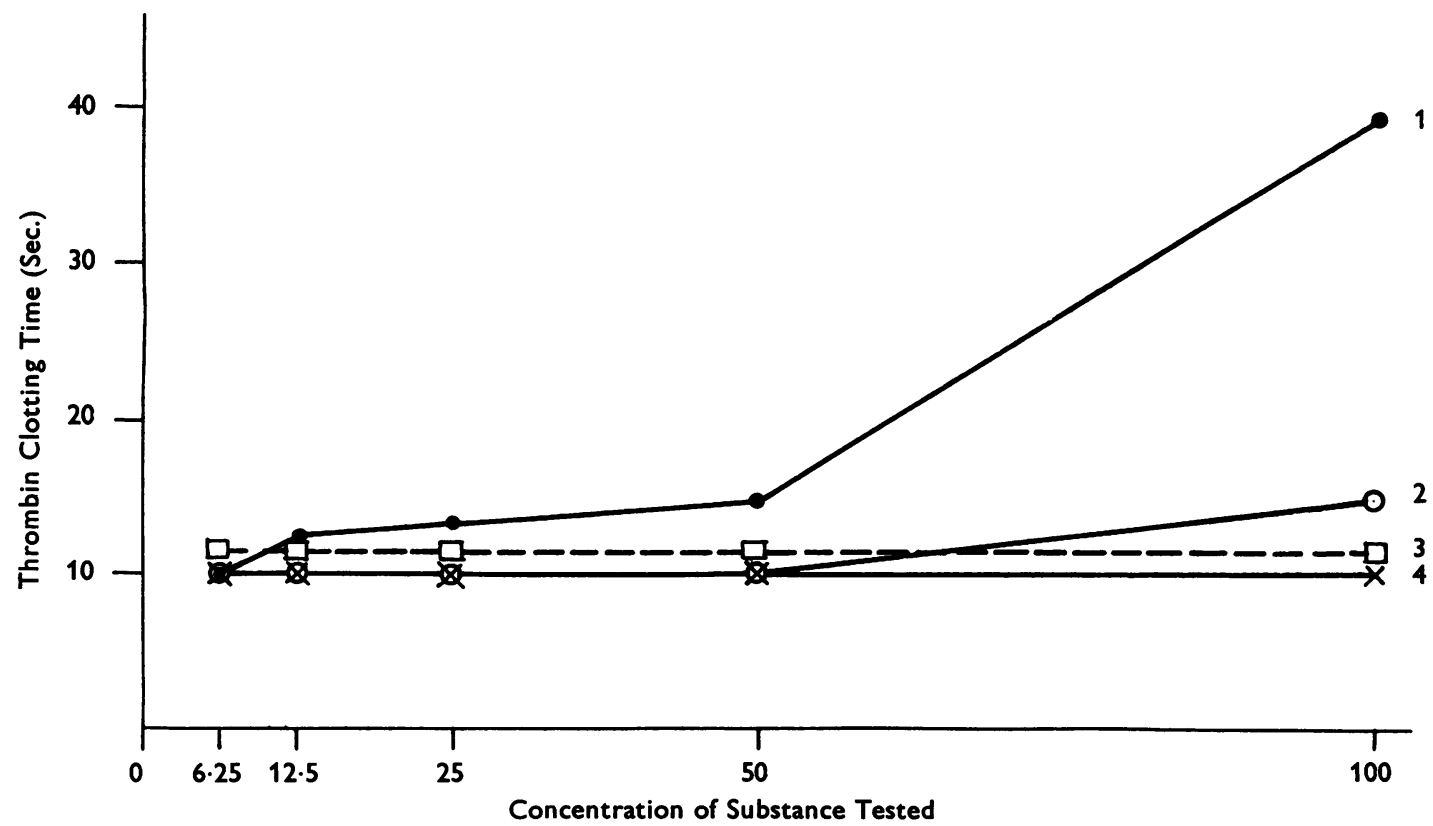

FIG. 4. Influence of bilirubin esters, free bilirubin, sodium salt of cholic acid, glycocholic acid, deoxycholic acid, and $\mathbb{\Phi}^{\circ}$ glucuronic acid on clotting time of $0.2 \%$ fibrinogen with thrombin. Initial concentrations: Bilirubin esters, 19 mg. $\% ; \stackrel{\odot}{\Phi}$ free bilirubin, $200 \mathrm{mg} . \%$; sodium glycocholate, sodium deoxycholate, glucuronic acid $100 \mathrm{mg} . \%$; and sodium salt of $\varrho$ cholic acid, $100 \mathrm{mg} . \%$. 


\section{TABLE I}

INFLUENCE OF BILIRUBIN GLUCURONIDES ON THROMBIN, PROTHROMBIN, AND RECALCIFICATION TIMES

\begin{tabular}{lcccc}
$\begin{array}{l}\text { Concentra- } \\
\text { tion of } \\
\text { Bilirubin- } \\
\text { glucuronides }\end{array}$ & Thrombin Time (sec.) & $\begin{array}{l}\text { Prothrombin } \\
\text { Time (sec.) }\end{array}$ & $\begin{array}{l}\text { Recalcification } \\
\text { Time (sec.) }\end{array}$ \\
\cline { 2 - 4 } $\begin{array}{l}\text { Solution } \\
\text { (mg. } \% \text { ) }\end{array}$ & & $\begin{array}{l}\text { 0.2\% } \\
\text { Fibrinogen }\end{array}$ & & \\
\hline 25 & & & & \\
$12 \cdot 5$ & 40 & 70 & 30 & 360 \\
$6 \cdot 25$ & 17 & 16 & 23 & 220 \\
$3 \cdot 12$ & 12 & 11 & 21 & 200 \\
Buffer & 11 & 10 & 19 & 170 \\
& 11 & 11 & 18 & 150
\end{tabular}

to differences in solubility of these substances in plasma protein solutions, or to a decrease in the level of free bilirubin in the presence of plasma protein.

Further studies are necessary to elucidate the detailed mechanism of the inhibitory action of bilirubin glucuronides.

The prolongation of the thrombin time in liver disorders may well be of a complex nature and due to several factors. An increase in fibrinolytic activity of blood in hepatic patients may result in the appearance of the fibrinogen digestion product antithrombin VI (Niewiarowski and Kowalski, 1958; Kowalski, 1960). The dysproteinaemia, particularly low albumin level and high $\gamma$ globulin level favour a prolongation of the thrombin time (Jim, 1957).
A raised level of bilirubin glucuronides could be one of the most specific factors influencing the thrombin time in the course of hepatic jaundice.

Measuring the prothrombin time is considered to be one of the most sensitive liver tests, for it permits the evaluation of the ability of liver parenchyma to synthesize plasma clotting factors. (It should be noted that the high levels of bilirubin glucuronides may interfere with the prothrombin time.) It is possible that the high level of bilirubin glucuronides in the plasma of icteric patients may be a contributory factor in the development of a haemorrhagic tendency.

\section{REFERENCES}

Alagille, D., and Soulier, J. P. (1957). Rev. int. Hépat., 7, 1.

Blombäck, B., and Blombäck, M. (1957). Ark. Kemi, 10, 415.

Cole, P. G., Lathe, G. H., and Billing B. H. (1954). Biochem. J., $57,514$.

Jim, R. T. S. (1957). J. Lab. clin. Med., 50, 45.

Kowalski, E. (1960). Thromb. Diath. haemorrh. (Stuttg.), Suppl. 4, p. 211.

Malloy, H. T., and Evelyn, K. A. (1937). Ibid, 119, 481.

Masure, R. (1956). VI Int. Congress of Hematology, Boston, Abstracts, p. 373 .

Niewiarowski, S., and Kowalski, E. (1958). Rev. Hémat., 13, 320

Quick, A. J. (1935). J. biol. Chem., 109, lxxiii.

Ratnoff, O. D. (1953). J. Lab. clin. Med., 42, 933.

Scheraga, H. A., and Laskowski, M. Jr. (1957). Advanc. Protein Chem., 12, 1.

Schmid, R. (1957). J. biol. Chem., 229, 881.

Schwarz, E., Wanner, J., and Koller, F. (1951). Acta haemat. (Basel), $6,70$.

Sokal, G., Schmid, F., and Hörder, M. H. (1955). Klin. Wschr., 33, 934. 